\title{
THE CHONDROGENIC DIFFERENTIATION POTENTIAL OF DENTAL PULP STEM CELLS
}

\author{
A. Longoni1 ${ }^{1,2}$, L. Utomo ${ }^{1,2}$, I.E.M. van Hooijdonk ${ }^{1}$, G.K.P. Bittermann', V.C. Vetter ${ }^{1}$, E.C. Kruijt Spanjer ${ }^{3}$, \\ J. Ross ${ }^{1}$, A.J.W.P. Rosenberg ${ }^{1}$ and D. Gawlitta ${ }^{1,2, *}$ \\ ${ }^{1}$ Department of Oral and Maxillofacial Surgery and Special Dental Care, University Medical Centre \\ Utrecht, Utrecht University, 3508 GA, Utrecht, the Netherlands \\ ${ }^{2}$ Regenerative Medicine Centre Utrecht, 3584 CT, Utrecht, the Netherlands \\ ${ }^{3}$ Department of Oral and Maxillofacial Surgery, Haaglanden Medical Centre, 2597 AX, the Hague, \\ the Netherlands
}

\begin{abstract}
Dental pulp stem cells (DPSCs) are particularly promising for tissue engineering (TE) due to the ease of their isolation procedure, great expansion potential and capability to differentiate towards several cell types of the mesodermal, ectodermal and endodermal lineages. Although several studies hint that DPSCs exhibit potential for cartilage tissue formation, the chondrogenic potential of DPSCs has only been marginally explored. Thus, the aim of the present study was to closely investigate the chondrogenic differentiation capacity of DPSCs for TE applications. More specifically, the potential of DPSCs for engineering hyaline and fibrous cartilage was determined.

DPSCs obtained from 7 human molars were expanded and chondrogenically differentiated in a 3D pellet culture model. After $21 \mathrm{~d}$ of differentiation with chondrogenic stimuli, DPSCs displayed glycosaminoglycan, aggrecan and limited collagen type II deposition. Cells presented an elongated morphology and produced a collagen-rich extracellular matrix, with a predominance of collagen type I in most of the samples, a characteristic of fibrous cartilage tissue. Variations in the administration periods of several chondro-inductive growth factors, including transforming growth factor beta 3, bone morphogenetic protein-2, $-6,-7$ and insulinlike growth factor-1, did not increase glycosaminoglycan or collagen type II deposition, typical markers of hyaline cartilage tissue. Furthermore, DPSCs could not be stimulated to go into hypertrophic chondrogenesis.

These results indicated that under a large variety of chondro-inductive culture conditions, DPSCs could form fibrocartilaginous tissues but not hyaline cartilage. Thus, DPSCs represent a valuable cell source for the regeneration of fibrocartilage in joints.
\end{abstract}

Keywords: Cartilage regeneration, hyaline, fibrous, neural-crest-derived stem cells, adult stem cell differentiation.

*Address for correspondence: Debby Gawlitta, PhD, University Medical Centre Utrecht, Department of Oral and Maxillofacial Surgery and Special Dental Care, room G05.129, PO Box 85500, 3508 GA Utrecht, the Netherlands.

Email: d.gawlitta@umcutrecht.nl

Copyright policy: This article is distributed in accordance with Creative Commons Attribution Licence (http://creativecommons.org/licenses/by-sa/4.0/).

\begin{tabular}{llll}
\hline & List of Abbreviations & CDM & chondrogenic differentiation \\
3D & three dimensional & COL1A1 & $\begin{array}{l}\text { collagen type I } \\
\text { collagen type II }\end{array}$ \\
ACAN & aggrecan & COL2A1 & collagen type X \\
ALP & alkaline phosphatase & COL10A1 & cartilage oligomeric matrix protein \\
$\alpha M E M$ & minimum essential medium $\alpha$ & COMP & 1,9-dimethyl-methylene blue \\
APC & allophycocyanin & DMMB & Dulbecco's modified Eagle medium \\
BMP & bone morphogenetic protein & DMEM & dental-pulp-derived stem cells \\
BSA & bovine serum albumin & DPSCs & ethylenediaminetetraacetic acid
\end{tabular}




$\begin{array}{ll}\text { FBS } & \text { foetal bovine serum } \\ \text { FITC } & \begin{array}{l}\text { fluorescein isothiocyanate } \\ \text { glycosaminoglycans } \\ \text { GAGs }\end{array} \\ \text { glyceraldehyde 3-phosphate } \\ \text { dehydrogenase } \\ \text { GFs } & \begin{array}{l}\text { growth factors } \\ \text { insulin-like growth factor-1 }\end{array} \\ \text { IGF-1 } & \text { insulin-transferrin-selenium } \\ \text { ITS } & \text { mesenchymal stem cells } \\ \text { MSCs } & \text { neural crest stem cells } \\ \text { NCSCs } & \text { phosphate-buffered saline } \\ \text { PBS } & \text { polymerase chain reaction } \\ \text { PCR } & \text { population doubling time } \\ \text { PDT } & \text { phycoerythrin } \\ \text { PE } & \text { SRY-Box 9 } \\ \text { Sox9 } & \text { tissue engineering } \\ \text { TE } & \text { transforming growth factor beta 1 } \\ \text { TGF- } \beta 1 & \text { temporomandibular joint } \\ \text { TMJ } & \end{array}$

\section{Introduction}

Since their first reported isolation (Gronthos et al., 2000), DPSCs have emerged as a particularly promising cell type for TE for several reasons (Anitua et al., 2018; Graziano et al., 2008). One of these reasons is the accessibility of the surgical site, as DPSCs can be isolated from routinely extracted third molars and potentially stored for further use, without additional donor site morbidity (Graziano et al., 2008; Kruijt Spanjer et al., 2017; Tirino et al., 2012). After extraction, DPSCs can be obtained from the pulp through enzymatic digestion or direct plating of minced pulp tissue (Hilkens et al., 2013). Previous work has demonstrated that these cells display a higher proliferation rate and higher colony forming efficiency in vitro than other types of multipotent stem cells in both humans (Gronthos et al., 2000; Ponnaiyan and Jegadeesan, 2014; Tamaki et al., 2013) and rats (Alge et al., 2010). Additionally, due to their neural crest origin, DPSCs have the potential to differentiate towards cell types belonging to the mesodermal, ectodermal and endodermal lineages, such as osteoblasts (Takebe et al., 2017; Zhang et al., 2006), odontoblasts (Gronthos et al., 2000), adipocytes (Takebe et al., 2017; Zhang et al., 2006), chondrocytes (Takebe et al., 2017; Zhang et al., 2006), myoblasts (Zhang et al., 2006), neurons (Zhang et al., 2006) and hepatocytes (Graziano et al., 2008; Nuti et al., 2016). In particular, their osteogenic and odontoblastic differentiation potential for intramembranous bone TE and dentistry applications is the most extensively studied (Anitua et al., 2018; Gronthos et al., 2000; La Noce et al., 2019; Morad et al., 2013; Nuti et al., 2016; Paino et al., 2017). In contrast, the chondrogenic potential of DPSCs for TE applications remains underexplored as most studies investigating DPSCs have only addressed their chondrogenesis as part of their multilineage differentiation potential for human (Hilkens et al., 2013; Koyama et al., 2009; Mokry et al., 2010; Takebe et al., 2017; Zhang et al.,
2006), murine (Grottkau et al., 2010) and porcine cells (Iohara et al., 2006). Nevertheless, investigating DPSC chondrogenic potential might be appealing, as the dental pulp and its stem cells originate from the NCSCs, which are also involved in the development of the TMJ disc (Chai et al., 2000) and Meckel's cartilage - the supportive, transient hyaline cartilage tissue present during embryonic development of the mammalian mandible (Chai et al., 2000). Thus, DPSCs might represent a promising cell source for cartilage TE. In particular, it is interesting to explore the suitability of DPSCs for the regeneration of hyaline cartilage and fibrocartilage. These two types of cartilage have different characteristics. Hyaline cartilage is typically found on the articulating surfaces of synovial joints such as knees and elbows, in the connection between ribs and sternum and in the respiratory system. It is composed of small numbers of chondrocytes dispersed in a matrix rich in GAGs and collagen type II (Sophia Fox et al., 2009). On the other hand, fibrocartilage is found in the TMJ, the intervertebral discs and the menisci. It is composed of a heterogeneous cell population, with most cells presenting a fibroblastic phenotype and the remainder being chondrocyte-like cells, which express chondrocyte markers but lack the typical hyaline pericellular matrix (Allen and Athanasiou, 2006). The smaller amount of GAGs and the predominance of collagen type I characterise the fibrocartilage matrix (Allen and Athanasiou, 2006).

By applying differentiation protocols developed for bone-marrow-derived MSCs, a variable chondrogenic potential of DPSCs is observed. In particular, depending on the donor and the culture conditions, DPSCs either fail to differentiate into chondrocytes (Pierdomenico et al., 2005; Sternberg et al., 2012) or are able to express typical chondrogenic differentiation markers, such as aggrecan (Spath et al., 2010; Takebe et al., 2017) and collagen type II (Koyama et al., 2009; Zhang et al., 2006), as well as to secrete GAGs in vitro (Nemeth et al., 2014; Spath et al., 2010; Takebe et al., 2017; Zhang et al., 2006). Discrepancies in the applied culture methods could partially explain these differences as, in a few studies, chondrogenesis was induced in a monolayer culture system (Alge et al., 2010; Alvarez et al., 2015; Pereira et al., 2012). Despite this, the in vitro model presents limitations when compared to 3D culture methods (e.g. pellet culture) (Caron et al., 2012; Yoo et al., 1998). Nevertheless, during chondrogenesis, DPSCs present a different gene expression profile from MSCs (Sternberg et al., 2012). Thus, similar to other types of MSC-like populations such as adiposederived stem cells (Puetzer et al., 2010), DPSCs might respond differently to chondrogenic stimuli. Therefore, differentiation protocols developed for MSCs might need to be further optimised to reveal the full chondrogenic potential of DPSCs.

It is uncertain whether differentiated DPSCs have the capability, as MSCs, to acquire a hypertrophic phenotype. This is particularly relevant when aiming 
Table 1. DPSC donor demographics and molar origin. - indicates unknown element number.

\begin{tabular}{|c|c|c|c|c|}
\hline Donor & Age & Sex & Molar origin & Element number \\
\hline A & 21 & Female & Maxilla & - \\
\hline B & 25 & Female & Mandible & - \\
\hline C & 20 & Male & Maxilla & - \\
\hline \multirow{2}{*}{ D } & \multirow{2}{*}{20} & \multirow{2}{*}{ Female } & Maxilla & 18 \\
\cline { 4 - 5 } & & & Maxilla & 28 \\
\cline { 4 - 5 } & & & Mandible & 38 \\
\hline E & 21 & Female & Mandible & 38 \\
\hline
\end{tabular}

at cartilage regeneration. If chondrocytes acquire a hypertrophic phenotype, they start secreting proangiogenic factors and metalloproteinases that promote blood vessel invasion and matrix remodelling upon in vivo implantation. Consequently, the cartilaginous TE construct could be eventually remodelled into bone, by following the endochondral ossification pathway (Collignon et al., 2019; Gawlitta et al., 2010).

A more systematic approach is required for exploring the chondrogenic potential of DPSCs. Thus, the aim of the present study was to closely investigate the chondrogenic differentiation potential of human DPSCs to evaluate the feasibility of their use for hyaline cartilage and fibrocartilage TE applications. To do so, the differentiation potential of DPSCs was characterised from 7 third molars. Furthermore, the differentiation protocol was tailored by comparing the effect of several chondro-inductive GFs. Finally, the potential of DPSCs to pursue hypertrophic chondrogenic differentiation was investigated.

\section{Materials and Methods}

\section{Isolation and expansion of human DPSCs}

DPSCs were obtained from the dental pulp of 7 extracted third molars from 5 patients at the University Medical Centrum Utrecht after acquiring their written informed consent (UMCU biobank, protocol number 15-149) (Table 1). Directly after extraction, the molars were sterilised in $70 \%$ ethanol and stored temporarily in sterile PBS containing 100 units/mL penicillin and $100 \mu \mathrm{g} / \mathrm{mL}$ streptomycin (pen/strep; Invitrogen). Subsequently, a slit was created in the enamel along the buccal and lingual grooves using a sterile dental aerator drill with a diamond burr. Next, the teeth were sterilised in $10 \%$ povidone-iodine (Fresenius-Kabi, Bad Homburg vor der Höhe, Germany) for 5 min and, subsequently, bifurcated with a dental elevator. Then, the dental pulp was removed from the pulp chamber, cut into pieces of approximately $1 \mathrm{~mm}^{3}$ and incubated for $3 \mathrm{~h}$ at $37^{\circ} \mathrm{C}$ and $5 \% \mathrm{CO}_{2}$ in $3 \mathrm{mg} / \mathrm{mL}$ collagenase type II (Worthington). A single cell suspension was obtained from the digests using a $70 \mu \mathrm{m}$ cell strainer. Cells were plated and cultured at $37^{\circ} \mathrm{C}$ and $5 \% \mathrm{CO}_{2}$ in expansion medium consisting of $\alpha \mathrm{MEM}$ (Gibco) supplemented with $10 \%$ heat-inactivated FBS (HyClone), $0.2 \mathrm{mM}$ L-ascorbic acid-2-phosphate (Sigma-Aldrich), $1 \%$ pen/strep and $1 \mathrm{ng} / \mathrm{mL}$ basic fibroblast growth factor (R\&D Systems). Medium was gently refreshed after $24 \mathrm{~h}$ to remove debris and every 3-4 d thereafter. DPSCs were cultured until $80 \%$ confluency and passaged at a density of 1,500 cells $/ \mathrm{cm}^{2}$. Human MSCs used as control were isolated and characterised as previously described (Gawlitta et al., 2012).

\section{Marker expression profile}

At passage 4, DPSCs were characterised for their surface and internal marker expression by flow cytometry using a FACS Canto II system (BD Biosciences). The presence of the MSC markers CD73 (PE-conjugated), CD90 (FITC-conjugated), CD105 (APC-conjugated) and CD271 (FITC-conjugated) along with the absence of the haematopoietic stem cell markers CD34 (APC-conjugated) and CD45 (PE-conjugated), the monocyte marker CD14 (FITCconjugated) and the B cell marker CD79 $\alpha$ (PEconjugated) were determined. All antibodies were purchased from Abcam. Additionally, the level of internally expressed neural crest marker nestin (PEconjugated; R\&D Systems) was examined in fixed and permeabilised cells. DPSCs were stained for $15 \mathrm{~min}$ at room temperature, shielded from direct light. Dilutions of the antibodies were used according to the manufacturer's instructions. Isotype-matched controls (Abcam) and unstained cells were included as negative controls for the gating strategy. For nestin, an additional control consisting of unstained, fixed and permeabilised cells was included. Data were analysed using FlowJo (version 10, Ashland, OR, USA). Gating of single, viable cells for the groups that were stained for the extracellular CD markers was based on the forward and sideward scatter dot plots of the unstained cell controls. Since the number of recorded events per sample varied, the flow cytometry data are presented normalised to the peak height (number of events), resulting in relative percentages. A minimum of 10,000 events were recorded for each flow cytometry measurement.

\section{Colony count and proliferation assay}

To assess the colony forming potential, primary isolated DPSC colonies containing more than 25 cells were counted under a microscope (DMi1; Leica) in 
duplicate. Data are presented as the mean of the two individual counts.

At passage 3, DPSCs were seeded at 1,500 cells/ $\mathrm{cm}^{2}$ and cultured in expansion medium for $7 \mathrm{~d}$ at $37^{\circ} \mathrm{C}$ in $5 \% \mathrm{CO}_{2}$. Afterwards, cells were harvested and counted in triplicate on at least three time points (ranging from 1 to $7 \mathrm{~d}$ after seeding). In order to determine the time points in between which the cells displayed exponential growth, the logarithmic average cell yield values were plotted against time. In this graph, the lag phase, log phase and stationary phase of cell growth were identified. The log phase (i.e. the linear region of this graph) was selected to calculate the PDT by applying the equation:

$$
P D T=\frac{(T y-T i) * \log (2)}{\log \left(\frac{Y}{I}\right)}
$$

where $T y=$ incubation time at end of log phase (h); $T i=$ incubation time at the start of log phase (h); $Y=$ cell number at the end of the log phase; $I=$ cell number at the start of the log phase.

\section{Three-lineage differentiation potential}

For osteogenic differentiation, DPSCs were cultured at passage 3 in monolayers in osteogenic differentiation medium [ $\alpha \mathrm{MEM}$ supplemented with $10 \%$ heatinactivated FBS, $0.2 \mathrm{mM}$ L-ascorbic acid-2-phosphate, $1 \%$ pen/strep, $10 \mathrm{mM} \beta$-glycerophosphate (SigmaAldrich) and $10 \mathrm{nM}$ dexamethasone (Sigma-Aldrich)] that was refreshed twice per week. After $7 \mathrm{~d}$, cells were fixed with $4 \%$ formaldehyde, permeabilised with $0.2 \%$ Triton- $X$ in Tris-buffered saline and stained for ALP activity using the Fuchsin+ SubstrateChromogen System (Dako) according to the manufacturer's instructions. Mineralisation was assessed at day 14 by staining the fixed monolayers with $2 \%$ alizarin red S ( $\mathrm{pH} 4$; Sigma-Aldrich) for 2 min. Images were acquired using a DMi1 microscope (Leica).

For adipogenic differentiation, DPSCs were cultured in monolayers in adipogenic differentiation medium [ $\alpha \mathrm{MEM}$ supplemented with $10 \%$ heatinactivated FBS, $1 \%$ pen/strep, $1 \mu \mathrm{M}$ dexamethasone, 0.5 mM3-isobutyl-1-methylxanthine (Sigma-Aldrich), $0.2 \mathrm{mM}$ indomethacin (Sigma-Aldrich) and $1.72 \mu \mathrm{M}$ insulin (Sigma-Aldrich)] that was changed twice a week. After $21 \mathrm{~d}$, cells were fixed in $10 \%$ formalin, washed with $60 \%$ isopropanol and stained with oil red O (Sigma-Aldrich) for $20 \mathrm{~min}$. Images were acquired using a DMi1 microscope.

For chondrogenic differentiation, DPSCs were centrifuged into pellets (200,000 cells/pellet) in polypropylene tubes (Greiner) and cultured in $500 \mu \mathrm{L}$ CDM consisting of high-glucose DMEM (Thermo Fisher Scientific) supplemented with $1 \%$ ITS + Premix (Corning), $0.1 \mu \mathrm{M}$ dexamethasone, $0.2 \mathrm{mM}$ L-ascorbic acid-2-phosphate, $1 \%$ pen/strep as previously described (Gawlitta et al., 2012). $10 \mathrm{ng} / \mathrm{mL}$ TGF- $\beta 1$ (PeproTech) was freshly added to the CDM. The medium was refreshed daily during the first $4 \mathrm{~d}$ after pellet formation, thereafter twice a week. After $21 \mathrm{~d}$ of culture, the pellets were fixed in $10 \%$ formalin, dehydrated, cleared in xylene and embedded in paraffin wax. $5 \mu \mathrm{m}$-thick sections (cut using a Microm HM340E microtome; Thermo Fisher Scientific) were deparaffinised with xylene and rehydrated. To assess GAG production, sections were stained with $0.04 \%$ toluidine blue solution (Sigma-Aldrich) in $0.1 \mathrm{M}$ sodium acetate ( $\mathrm{pH} 4$; Sigma-Aldrich) and counterstained with $0.2 \%$ fast green (Sigma-Aldrich). To evaluate collagen deposition, sections were stained with alcian blue ( $\mathrm{pH} 2.5$; Sigma-Aldrich) and picrosirius red (Klinipath, Duiven, the Netherlands). Images were acquired using an Olympus BX51 microscope and Olympus DP70 camera.

\section{Gene expression analysis}

DPSCs $[n=3$, donor $\mathrm{A}, \mathrm{D}(28)$ and E] were expanded and harvested at passage 4 to form pellets as described above. After $21 \mathrm{~d}$ of chondrogenic induction, pellets were mechanically crushed, using pestle and mortar, in TRIzol reagent (Thermo Fisher Scientific) and mRNA was isolated from the aqueous phase obtained, according to the manufacturer's instructions. DNA contaminations were removed by a DNAse treatment (Turbo DNAse; Thermo Fisher Scientific), according to the manufacturer's instructions. mRNA was quantified using a NanoDrop ND1000 spectrophotometer (Thermo Fisher Scientific) at 260/280 nm. cDNA was synthesised using the iScript cDNA Synthesis Kit (Bio-Rad) according to the manufacturer's instructions. Gene expression analysis of SOX9, COMP, ACAN, COL1A1, COL2A1 and COL10A1 was done on a Bio-Rad CFX96 Real-

Table 2. List of primers used.

\begin{tabular}{|c|c|c|}
\hline Gene & Primer forward $\left(\mathbf{5}^{\prime} \mathbf{-} \mathbf{3}^{\prime} \mathbf{)}\right.$ & Primer reverse $\mathbf{( 5}^{\prime} \mathbf{- 3}^{\prime} \mathbf{)}$ \\
\hline SOX9 & CAACGCCGAGCTCAGCA & TCCACGAAGGGCCGC \\
\hline COMP & CCCCAATGAAAAGGACAACTGC & GTCCTTTTGGTCGTCGTTCTTC \\
\hline ACAN & ATGTTCCCTGCAATTACCACCT & TTGATCTCATACCGGTCCTTCTTC \\
\hline$C O L 1 A 1$ & AAGAGGAAGGCCAAGTCGAG & GTTTCCACACGTCTCGGTCA \\
\hline$C O L 2 A 1$ & GCCTCAAGGATTTCAAGGCAAT & GCTTTTCCAGGTTTTCCAGCTT \\
\hline COL10A1 & CAAGGCACCATCTCCAGGAA & AAAGGGTATTTGTGGCAGCATATT \\
\hline GAPDH & ATGGGGAAGGTGAAGGTCG & TAAAAGCAGCCCTGGTGACC \\
\hline
\end{tabular}


Time PCR Detection System (Bio-Rad) using FastStart SYBR Green Master mix (Sigma-Aldrich). GAPDH was used as a housekeeping gene and the relative expression was determined by the $2^{-\Delta C T}$ method. Values above cycle 40 were considered undetectable. Primers used are listed in Table 2.

Tailoring the DPSC chondrogenic differentiation protocol for hyaline cartilage

DPSCs $[n=3$, donor A, D(28) and E] were expanded and harvested at passage 4 to form pellets $(500,000$ cells/pellet) in round-bottom, Corning ${ }^{\circledR}$ Costar $^{\circledR}$ Ultra-Low Attachment 96-well plates. Different GFs associated with chondrogenesis were evaluated for their potential to stimulate GAG and collagen deposition when supplemented to the CDM, either singularly or in combinations. The screened GFs and their respective concentrations were: $10 \mathrm{ng} / \mathrm{mL}$ TGF-33 (PeproTech), 100 ng/mL BMP-2 (InductOS, Wyeth/Pfizer, New York, NY, USA), 100 ng/mL BMP6 (PeproTech), 100 ng/mL BMP-7 (PeproTech) and 100 ng/mL IGF-1 (PeproTech). Pellets of each donor were divided into three groups. In the first group, pellets received only one single GF during the whole culture period (i.e. TGF- $\beta 3$, BMP-2, BMP-6, BMP-7 or IGF-1). In the second group, pellets received a continuous combination of TGF- $\beta 3$ and one of the BMP isotypes or IGF-1 (i.e. TGF- $\beta 3$ + BMP-2, TGF- $\beta 3$ + BMP-6, TGF- 33 + BMP-7, TGF- $\beta 3$ + IGF-1). The third group of pellets was stimulated with a cyclic alternating pattern of TGF- $\beta 3$ and one of the BMP isotypes or IGF-1 (i.e. TGF- $\beta 3$ and BMP-2, TGF- $\beta 3$ and BMP-6, TGF- $\beta 3$ and BMP-7, TGF- $\beta 3$ and IGF- 1 ). A schematic representation of the different medium changes is available in Fig. 1. Pellets cultured in CDM without any additional GF were included as negative controls. After $28 \mathrm{~d}, 2$ pellets per group were processed for histological analysis as described in the previous paragraph. 3 other pellets were digested overnight at $60^{\circ} \mathrm{C}$ in papain digestion buffer $[250 \mu \mathrm{g} /$ $\mathrm{mL}$ papain, $0.2 \mathrm{M} \mathrm{NaH}_{2} \mathrm{PO}_{4^{\prime}}$ 0.1 EDTA and 0.01 M DLcysteine hydrochloride (all Sigma-Aldrich)]. The total amount of GAGs was determined using the DMMB ( $\mathrm{pH}$ 3.0; Sigma-Aldrich) assay (Farndale et al., 1986). Chondroitin sulphate C (Sigma-Aldrich) was used as standard and the absorbance was measured. The sulphated GAG content was expressed as the ratio between the 525 and $595 \mathrm{~nm}$ absorbance values. To normalise the GAG content, DNA was quantified using a Quant-iT Picogreen dsDNA assay (Thermo Fisher Scientific) according to the manufacturer's instructions.
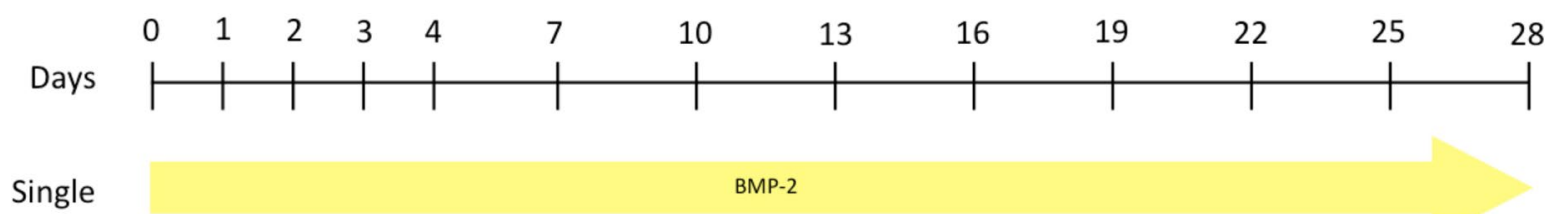

$\begin{array}{ll}\text { Combined } & \text { BMP-2 } \\ \text { TGF- } \beta 3\end{array}$

\begin{tabular}{|l|l|l|l|l|l|l|l|l|l|l|l|} 
Cycled & TGF- $\beta 3$ BMP-2TGF- $\beta 3$ BMP-2 & TGF- $\beta 3$ & BMP-2 & TGF- $\beta 3$ & BMP-2 & TGF- $\beta 3$ & BMP-2 & TGF- $\beta 3$ & BMP-2 \\
\hline
\end{tabular}

Fig. 1. Schematic representation of the three different patterns of medium change. BMP-2 is used as an example to explain the patterns. The same patterns were applied for BMP-2, BMP-6, BMP-7 and IGF-I, all in combination with TGF- $\beta 3$. After $28 \mathrm{~d}$ of culture, samples were harvested and processed for analysis.

a

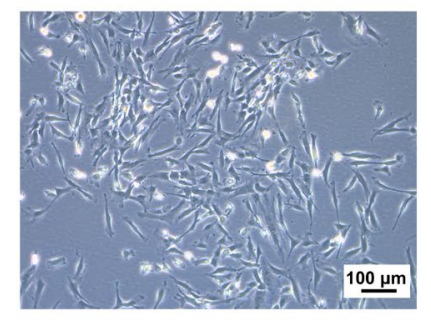

b

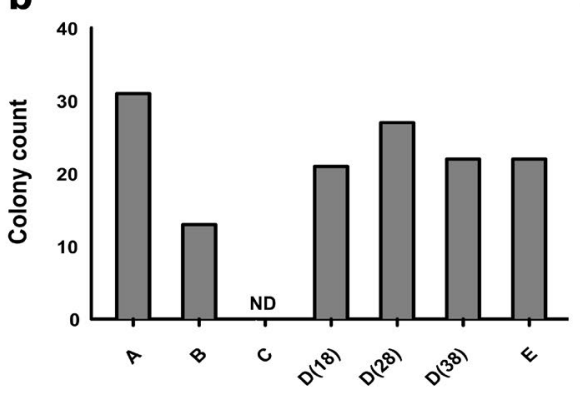

C

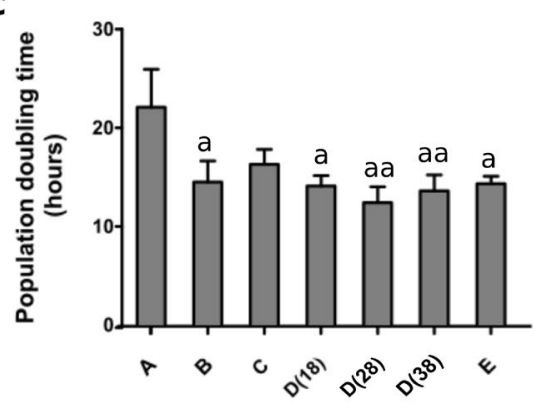

Fig. 2. DPSCs characterisation after isolation. (a) Representative images of DPSCs fibroblastic morphology and (b) number of colonies (mean of two individual countings of the same DPSC culture) formed by primary DPSCs. (c) Proliferation potential of all DPSC cultures expressed as PDT determined at passage 3. Statistical differences are shown as a $p \leq 0.01$, aa $p \leq 0.001$. ND: not determined because individual colonies could not be distinguished. 


\section{Hypertrophy induction}

To assess whether chondrogenically stimulated DPSCs were capable of responding to hypertrophic induction, pellets were formed at passage 4 , as described above $[n=3$, donor A, D(28) and E]. Since none of the tested (pattern of) GFs outperformed the others in terms of GAG deposition, chondrogenic differentiation was carried out by supplementing the medium with TGF- $\beta 3$. After $28 \mathrm{~d}$, the medium was changed to hypertrophic induction medium consisting of high-glucose DMEM supplemented with $1 \%$ ITS + Premix, $1 \mathrm{nM}$ dexamethasone, $0.2 \mathrm{mM}$ L-ascorbic acid-2-phosphate, $1 \%$ pen/strep, $10 \mathrm{mM}$ $\beta$-glycerophosphate and $1 \mathrm{nM}$ triiodothyronine (Sigma-Aldrich) for 7 additional days. At day 35, pellets were fixed and processed for histology as described above. In addition to toluidine blue staining, collagen type $\mathrm{X}$ immunostaining and von Kossa staining for mineralisation were performed to assess hypertrophic matrix formation. von Kossa staining was done by incubating the sections for $1 \mathrm{~h}$ with $1 \%$ silver nitrate (Sigma-Aldrich) directly under a light bulb (Philips Master TL5 HO 54W 830, $1 \mathrm{~m}$ distance). Subsequently, the samples were washed with $5 \%$ sodium thiosulphate (Alta Aesar, Haverhill, MA, USA) and counterstained with haematoxylin.
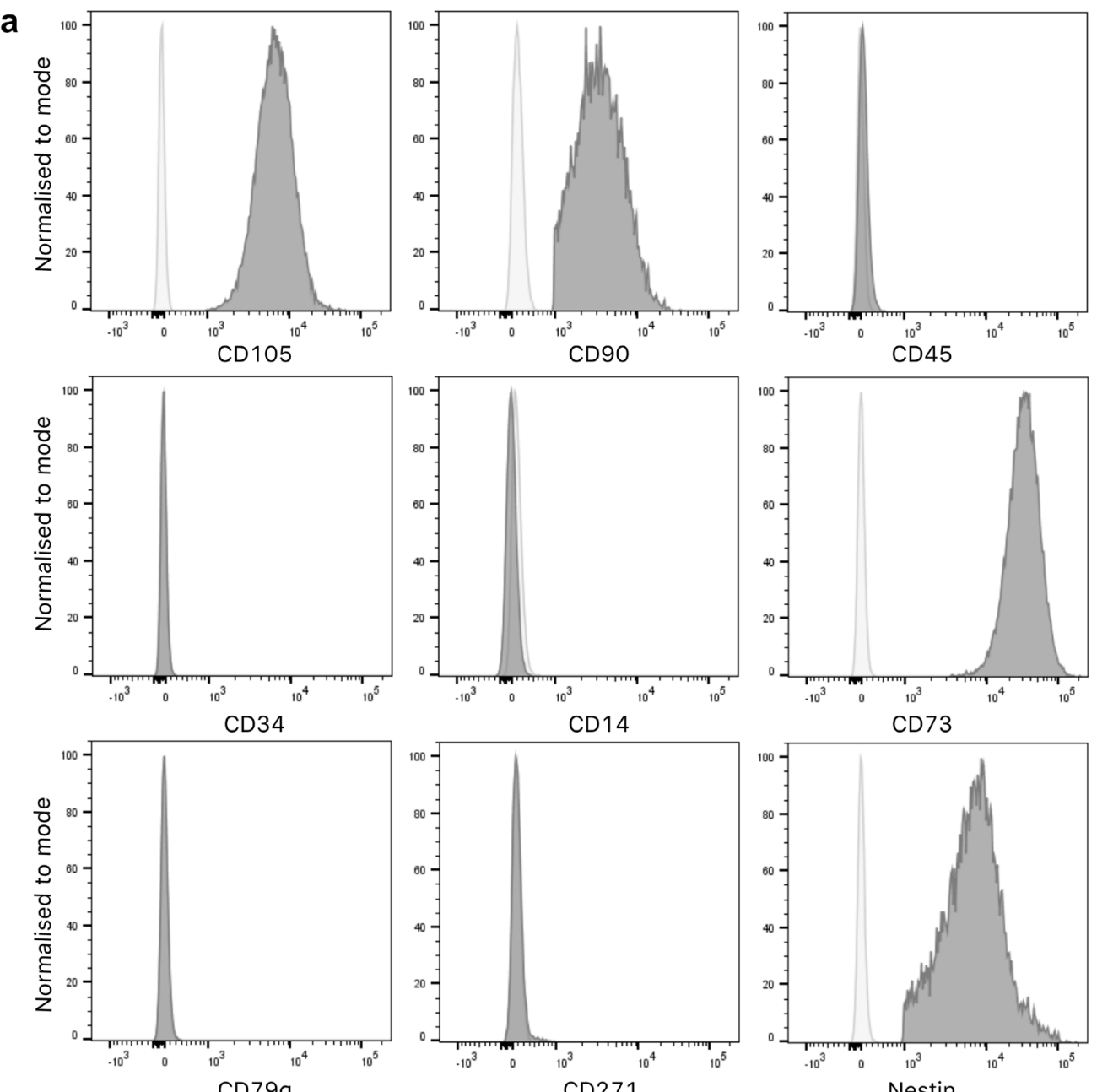

b

CD79a

$\mathrm{CD} 271$

\begin{tabular}{|c|c|c|c|c|c|c|c|c|c|}
\hline Donor & CD105 & CD90 & CD45 & CD34 & CD14 & CD73 & CD79 $\alpha$ & CD271 & Nestin \\
\hline A & 99.7 & 90.3 & 0 & 0 & 0 & 99.9 & 0 & 9.6 & 93.7 \\
\hline B & 100 & 99.6 & 0 & 0 & 0 & 99.5 & 0 & 1.7 & 96.2 \\
\hline C & 99.7 & 90.2 & 35.3 & 1.4 & 0 & 99.9 & 0 & 1.4 & 99.6 \\
\hline D(18) & 99.6 & 95.1 & 0.1 & 0 & 0 & 99.9 & 0.2 & 6.8 & 92.3 \\
\hline D(28) & 99.8 & 93.7 & 0 & 0.1 & 0 & 99.9 & 0.2 & 3.2 & 98.5 \\
\hline D(38) & 99.6 & 70.6 & 0 & 0 & 0 & 99.8 & 0.1 & 2.2 & 99.4 \\
\hline E & 99.8 & 90.9 & 0 & 0 & 0 & 99.9 & 0.1 & 2.9 & 99.7 \\
\hline
\end{tabular}

Fig. 3. Expression of stem cell surface markers per DPSC culture. (a) An example of the graphs obtained from donor E (dark grey) and the relative isotype controls (light grey). (b) Percentage of positive cells for mesenchymal, haematopoietic and neural crest cell markers are depicted for DPSCs derived from the different donors. 


\section{Immunohistochemistry}

To define the collagen types present in the matrix, immunohistochemical staining with primary antibodies directed against aggrecan (Novus Biologicals, Centennial, CO, USA), collagen type I (Abcam), collagen type II (DSHB, University of Iowa, Iowa City, IA, USA) and collagen type X (Quartett, Berlin, Germany) was performed. All sections were deparaffinised and rehydrated as described above. For aggrecan and collagen type I stainings, antigens were retrieved by boiling the samples for $15 \mathrm{~min}$ at $95^{\circ} \mathrm{C}$ in $10 \mathrm{nM}$ citrate buffer For collagen type II detection, antigens were retrieved by treating the sections at $37^{\circ} \mathrm{C}$ with $1 \mathrm{mg} / \mathrm{mL}$ pronase (Sigma-Aldrich) and $10 \mathrm{mg} / \mathrm{mL}$ hyaluronidase (Sigma-Aldrich) for $30 \mathrm{~min}$ each. Finally, for collagen type $X$ staining, antigens were retrieved by sequential incubation for $2 \mathrm{~h}$ with $1 \mathrm{mg} / \mathrm{mL}$ pepsin (Sigma-Aldrich) at $\mathrm{pH} 2.0$ and for $30 \mathrm{~min}$ with $10 \mathrm{mg} / \mathrm{mL}$ hyaluronidase, both at $37^{\circ} \mathrm{C}$. The endogenous peroxidase activity was blocked by treating the sections for $10 \mathrm{~min}$ with $0.3 \% \mathrm{H}_{2} \mathrm{O}_{2}$ solution. Furthermore, to prevent aspecific binding, the samples were incubated with $5 \%$ BSA (Roche) in PBS for $30 \mathrm{~min}$. Primary antibodies were diluted in $5 \%$ BSA/PBS (1: 150 aggrecan, $3 \mu \mathrm{g} / \mathrm{mL}$ collagen type I, $0.6 \mu \mathrm{g} / \mathrm{mL}$ collagen type II, $10 \mu \mathrm{g} / \mathrm{mL}$ collagen type $X$ ) and incubated overnight at $4{ }^{\circ} \mathrm{C}$. Mouse isotypes (Dako) were used as negative controls at concentrations or dilutions matched with those of the primary antibodies. Samples were incubated for $30 \mathrm{~min}$ at room temperature with EnVision+ System-HRP labelled secondary antibody (Dako). Antigen detection was performed by incubation with 3,3'-diaminobenzidine tetrahydrochloride hydrate for no longer than $10 \mathrm{~min}$. Sections were counterstained with 1:1 Mayer's haematoxylin in deionised water (Merck), dehydrated and mounted with permanent mounting medium (Depex; Merck).

\section{Statistical analysis}

GAG/DNA-ratios are presented as means of at least three biological replicates and their standard deviations. A randomised block design with Bonferroni post-hoc analysis was applied to the GAG/ DNA ratios, absolute DNA values and absolute GAG content, in order to evaluate statistical differences between groups. An unpaired t-test with Welch's correction was performed in order to evaluate the differences in gene expression between DPSCs and MSCs. SPSS (version 24, IBM) was used for all statistical analyses. Statistical significance was defined as $p<0.05$.

\section{Results}

\section{DPSC isolation and characterisation}

7 cultures were successfully established from the dental pulp tissue derived from 5 healthy human donors (Table 1). Cells adhering to the tissueculture plastic were visible within a maximum of $9 \mathrm{~d}$ after plating the tissue digests and grew out into distinct colonies. The numbers of colonies formed and the proliferation rates varied between DPSCs isolated from different donors (Fig. $\mathbf{2 b}, \mathbf{c}$ ). After the first passage, all DPSCs displayed an elongated, fibroblastic morphology (Fig. 2a). Most DPSC cultures expressed cell surface markers (> $90 \%$ positive) associated with mesenchymal stem cells, including CD105, CD90 and CD73 and no expression

\section{Adipogenic}

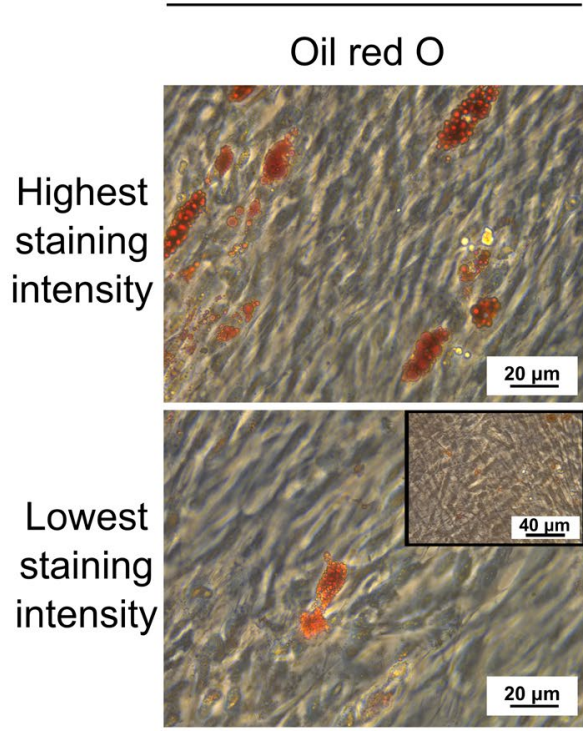

Osteogenic

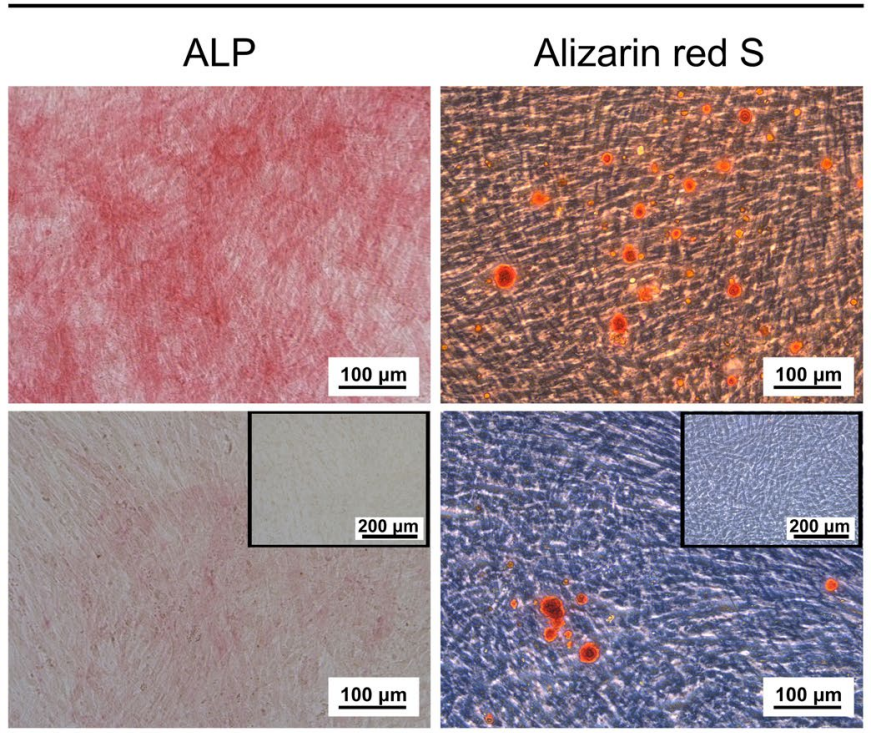

Fig. 4. Microscopical evaluation of the differentiation potential of DPSCs towards the adipogenic and osteogenic lineages. Variations in lipid vacuole formation (orange/red vesicles), ALP activity (red staining) and mineralised nodule (bright red nodules) formation were observed between the DPSCs derived from different donors and within cultures derived from the same donor. Inserts represent the negative undifferentiated controls. 


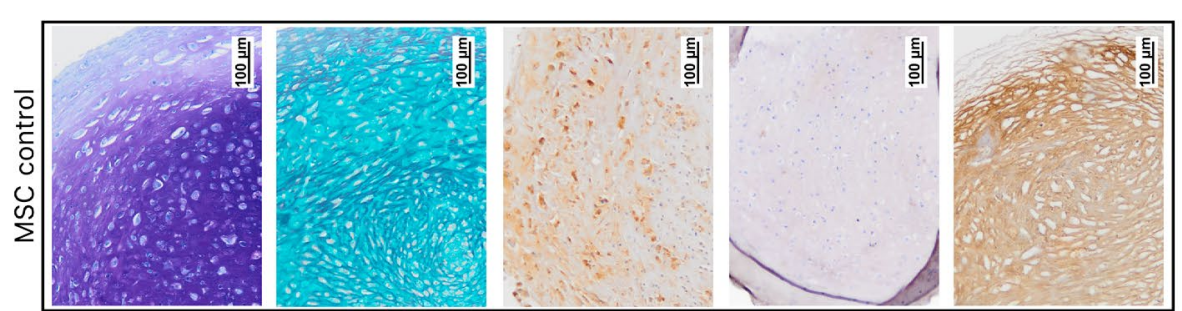

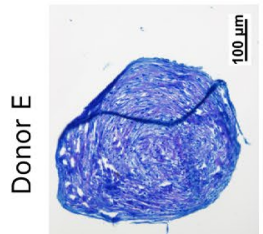
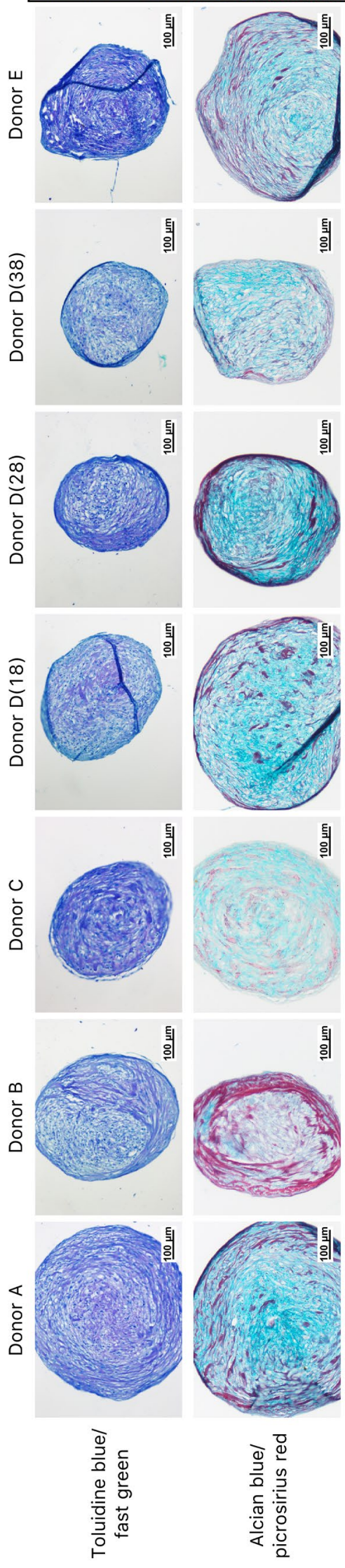
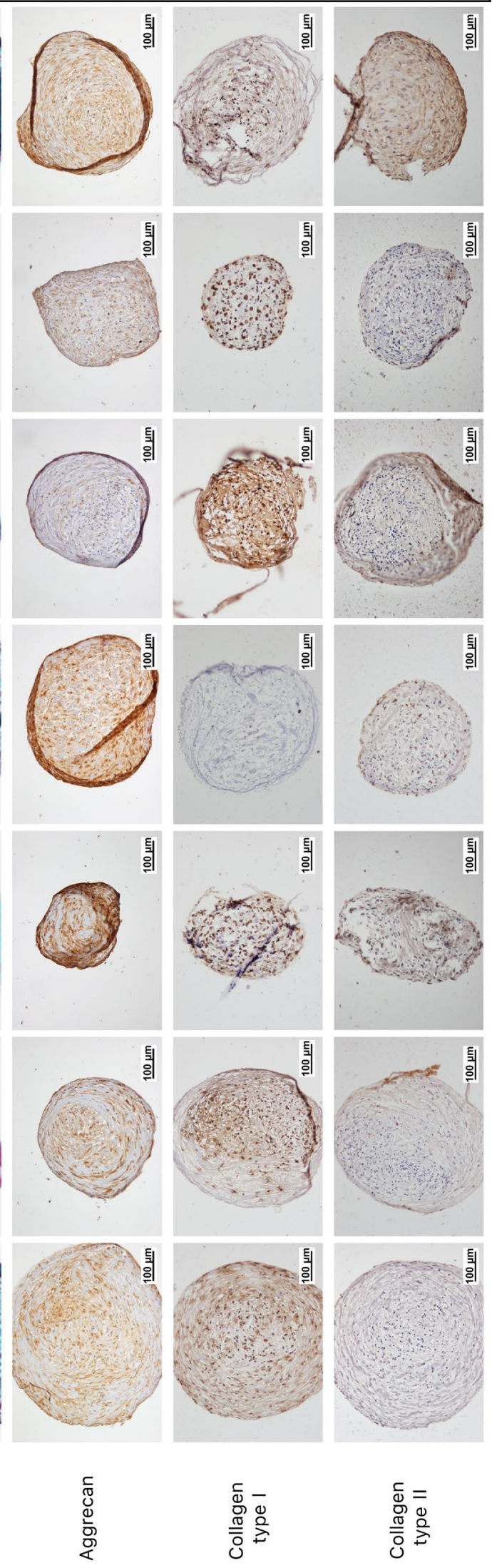

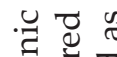

0.00

它

ปै.

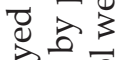

बे

की

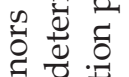

要

तี 3

용

$\stackrel{5}{\circ}$

论 范

กิ \&

क.

范

웡

䒕至

के

ㅊ.

च

ฮี ฮี

造造

촐

듀 శ్

نे

完

要

प क ज

즐 응

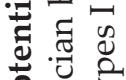

웅

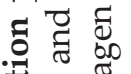

.

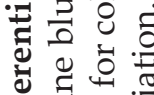

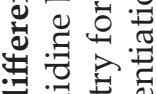

话.

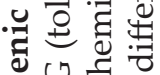

60 U

뉸.

츠응

원

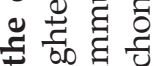

Ч

उ

न के के

远

○. ․ㅗ

ம

舟艺焉 
( $<1.0 \%$ positive) of the haematopoietic stem cell markers CD34 and CD45, monocyte marker CD14 and B cell marker CD79 $\alpha$ (Fig. 3). Additionally, most of the DPSCs were positive for the neural crest marker nestin. Finally, CD271 was only expressed in a small subpopulation of each DPSC culture (1.4-9.6 \%). After characterisation, DPSC s from donor $\mathrm{C}$ were excluded from further experiments as a relatively large cell population was positive for CD45 (35.3\%), suggesting the presence of a haematopoietic subpopulation.

In contrast to the limited donor variation observed with respect to proliferation potential (Fig. 2), the
DPSCs exhibited heterogeneous differentiation capacity (Fig. 4,5). Overall, all osteogenically stimulated DPSC cultures displayed ALP activity, an early osteogenesis marker, to various extents and mineralisation nodules, a late osteogenesis marker. More variation was observed when DPSCs were differentiated towards the adipogenic lineage as the presence of intracellular lipid vesicles was observed in 5 out of 7 DPSC cultures. GAGs and aggrecan were present in all DPSC pellets after chondrogenic induction, although inter- and intra-donor variation was observed (Fig. 5). Furthermore, for most DPSC

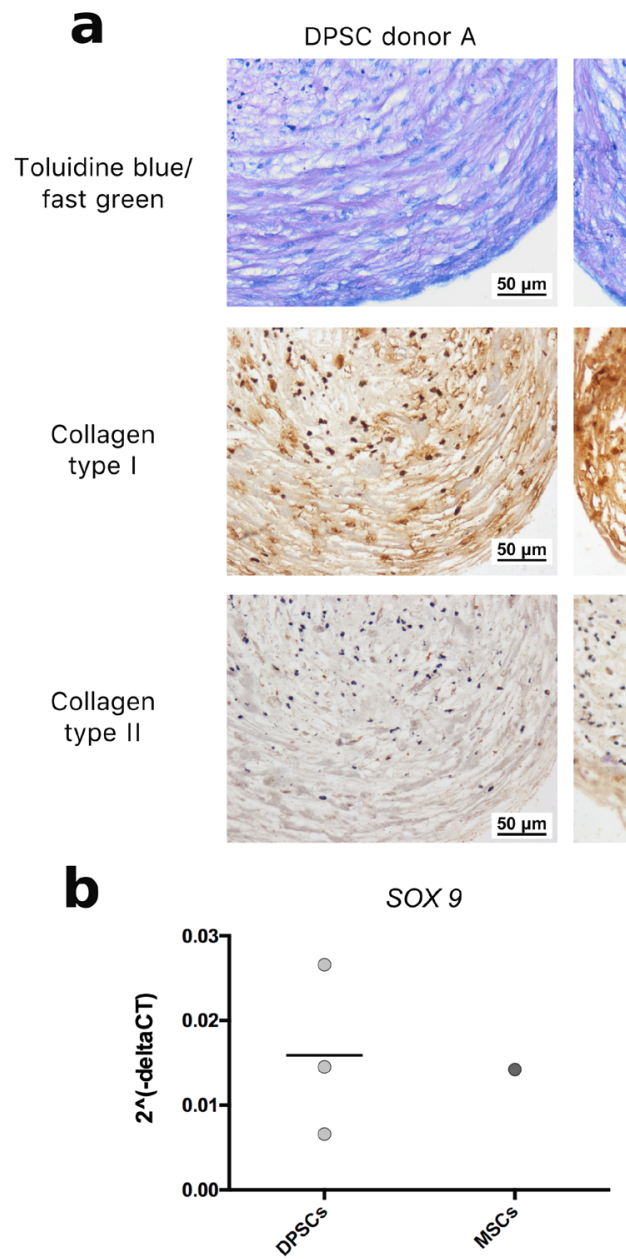

COL2A1

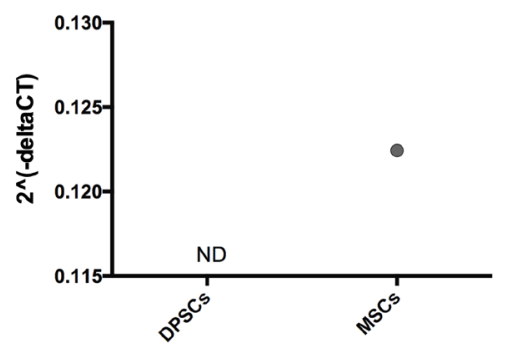

DPSC donor D(28)
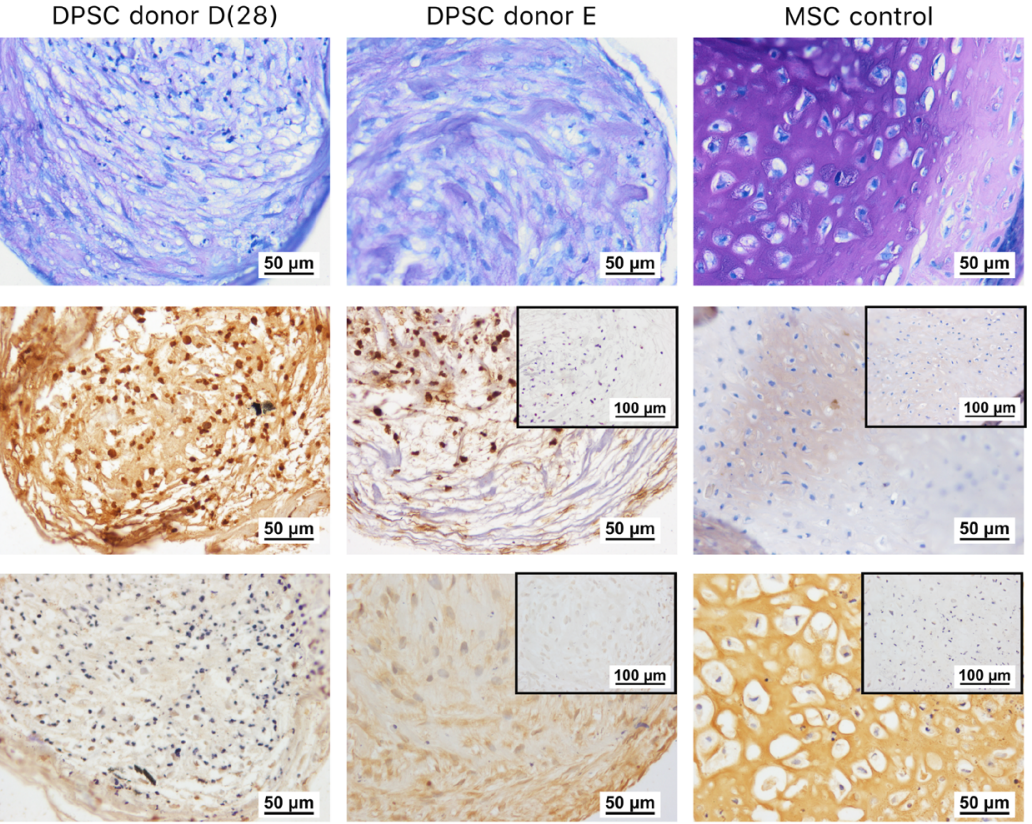

COMP
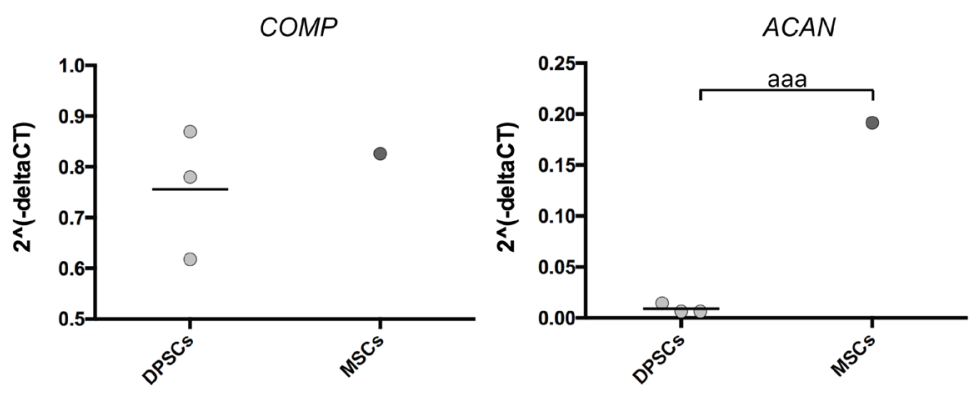

COL1A1
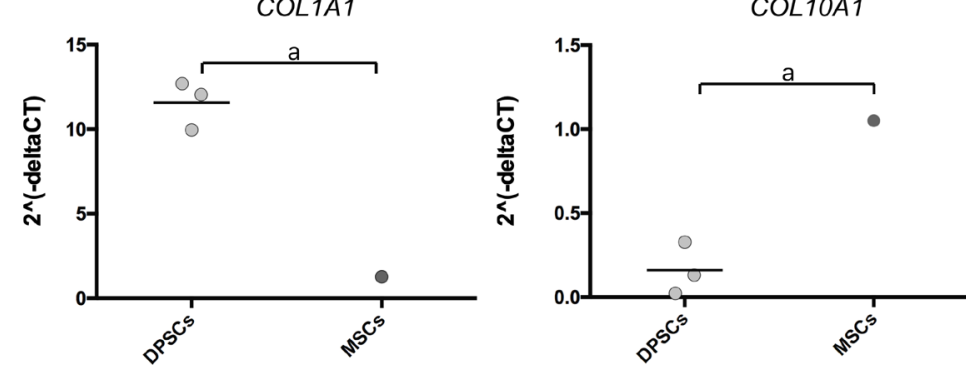

Fig. 6. Evaluation of cell morphology and expression of chondrogenic markers for 3 DPSC donors. (a) A higher magnification of the toluidine-blue-stained sections highlighted the absence of the typical chondrocyte lacunae. Furthermore, the presence of collagen type I and II was highlighted when compared to the isotypes control depicted in the inserts. (b) Gene expression analysis confirmed the presence of chondrogenic markers after $21 \mathrm{~d}$. MSC pellets cultured with the same differentiation protocol were included as a positive chondrogenic control. Dots represent the expression of the individual donors. ND: not detectable. Statistical differences are shown as a $p \leq 0.05$, aa $p \leq 0.001$. 
pellets, collagen type I was most distinctly present in the ECM when compared to collagen type II (Fig. 5). Gene expression analysis of the DPSCs confirmed the presence of chondrogenic markers including SOX9, $C O M P$ and $A C A N$ in the pellet cultures derived from 3 donors. Consistent with the immunohistochemistry results, COL1A1 expression was upregulated in all cases. In contrast, COL2A1 expression was undetectable after $21 \mathrm{~d}$ of differentiation (Fig. 6). In addition, the DPSCs adopted a flattened morphology, indicative of fibrocartilage formation, rather than a round morphology in lacunae (Fig. 6), a characteristic of hyaline cartilage tissue.

\section{Assessing DPSC potential for hyaline cartilage differentiation}

To evaluate whether DPSCs also possessed the capacity to differentiate into the hyaline chondrogenic lineage in vitro, additional formulations and various patterns of exposure to chondro-inductive media were evaluated.

Overall, the toluidine blue staining highlighted the GAG deposition for the different GFs and patterns of exposure (Fig. 7a). No statistically significant differences were found in the GAG/DNA-ratios of the pellets that were cultured with the evaluated factors applied singularly or in an alternating pattern with TGF- $\beta 3$ (Fig. 7b,c). Interestingly, the GAG/DNA-ratio of pellets exposed only to CDM was comparable to those receiving GFs in a singular or cycled fashion
(Fig. 7b,c). Furthermore, pellets that received a BMP isotype combined with TGF- $\beta 3$ (Fig. 7d) displayed the lowest GAG/DNA-ratio. Immunohistochemical evaluation highlighted that none of the conditions promoted extensive collagen type II deposition, while collagen type I remained an abundant component of the ECM in all conditions (Fig. 8). In addition, cells remained flat and were not enclosed in lacunae.

\section{DPSCs did not differentiate into the hypertrophic chondrogenic phenotype}

Although differentiation into the hyaline cartilage lineage appeared limited, whether DSPCs were at all capable of continuing differentiation along this lineage into the hypertrophic chondrogenic phenotype was explored. Toluidine blue staining confirmed GAG production. However, no mineral deposition or collagen type $X$ was present in the ECM of the pellets that were either exposed to chondrogenic medium only or to hypertrophic medium (Fig. 9).

\section{Discussion}

Stem cells derived from the cranial neural crest, which during development are involved in the formation of Meckel's cartilage and TMJ disc, can still be found after birth in the dental pulp (Chai et al., 2000). Thus, the use of DPSCs was explored in the context
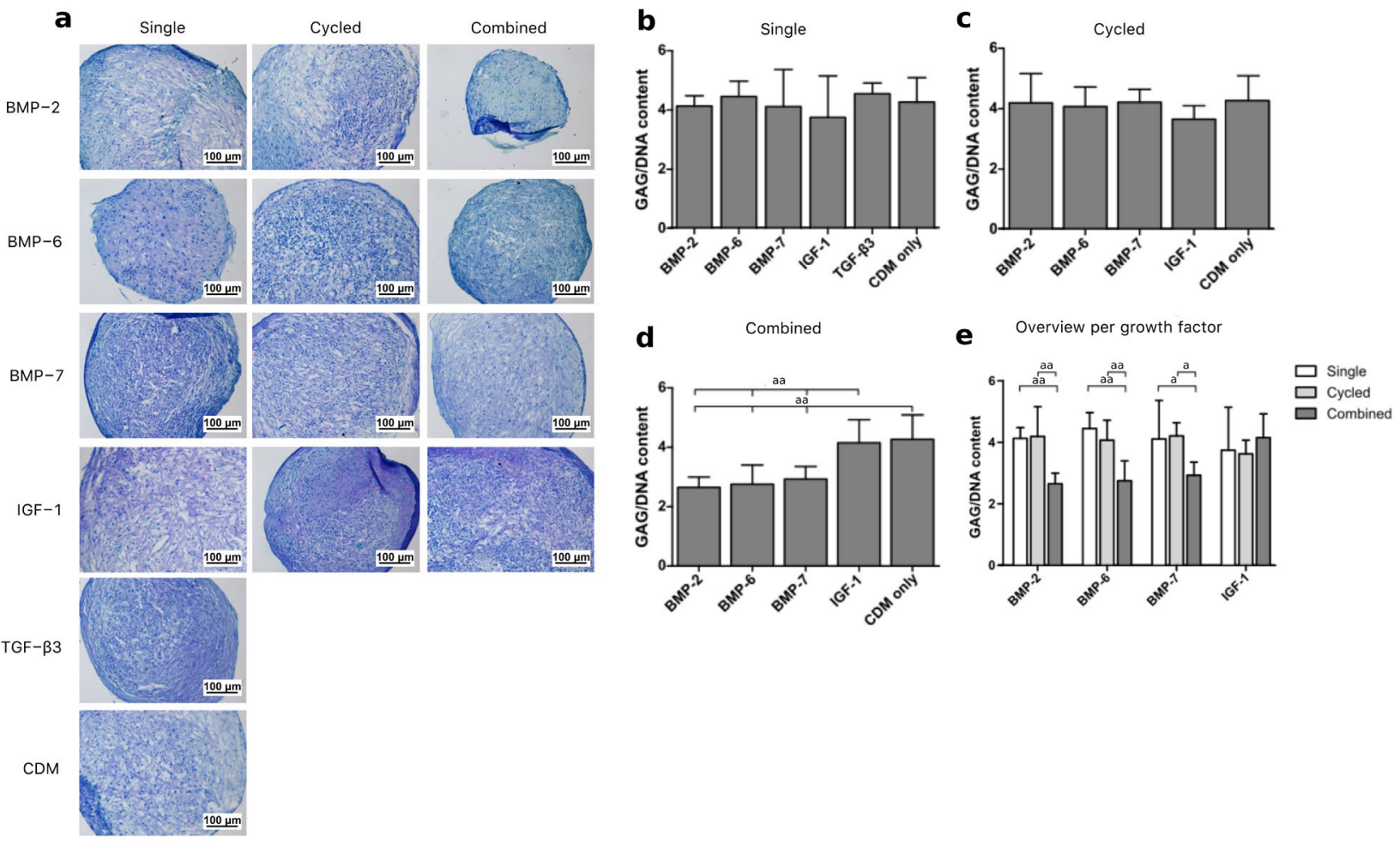

Fig. 7. Effect of the different GFs and their administration patterns on GAG deposition. (a) Toluidine blue staining highlighted GAG deposition in all conditions. GAG/DNA ratios when GFs were applied (b) singularly, (c) in an alternating cyclic pattern or (d) combined. (e) Combined overview. In the cycled group, GFs were alternated with TGF- $\beta 3$ whereas, in the combined group, they were supplemented together with TGF- 33 . No GFs were added in the CDM group. Statistical differences are shown as a $p \leq 0.01$, aa $p \leq 0.001$. 
of cartilage TE for maxillofacial applications. In particular, the present study extensively analysed the DPSC capacity to form hyaline and fibrous cartilage in vitro by applying various differentiation regimes.

DPSC pellets derived from all 7 third molars extracted produced an ECM consisting of GAGs, aggrecan and collagen types I and II, which was consistent with other reports (Grottkau et al., 2010; Iohara et al., 2006; Koyama et al., 2009; Zhang et al., 2006). This, together with the expression of SOX9 and COMP, confirmed the competence of these cells to differentiate toward the chondrogenic lineage. However, histological analysis identified collagen type I as the predominant collagen type of the ECM in most of the cultures. Consistently, expression of COL1A1 was also upregulated. Additionally, DPSCs displayed an elongated morphology typical of the fibroblast-like cells residing in the TMJ disc (Allen and Athanasiou, 2006). In contrast, GAG and collagen type II deposition was limited when compared to the

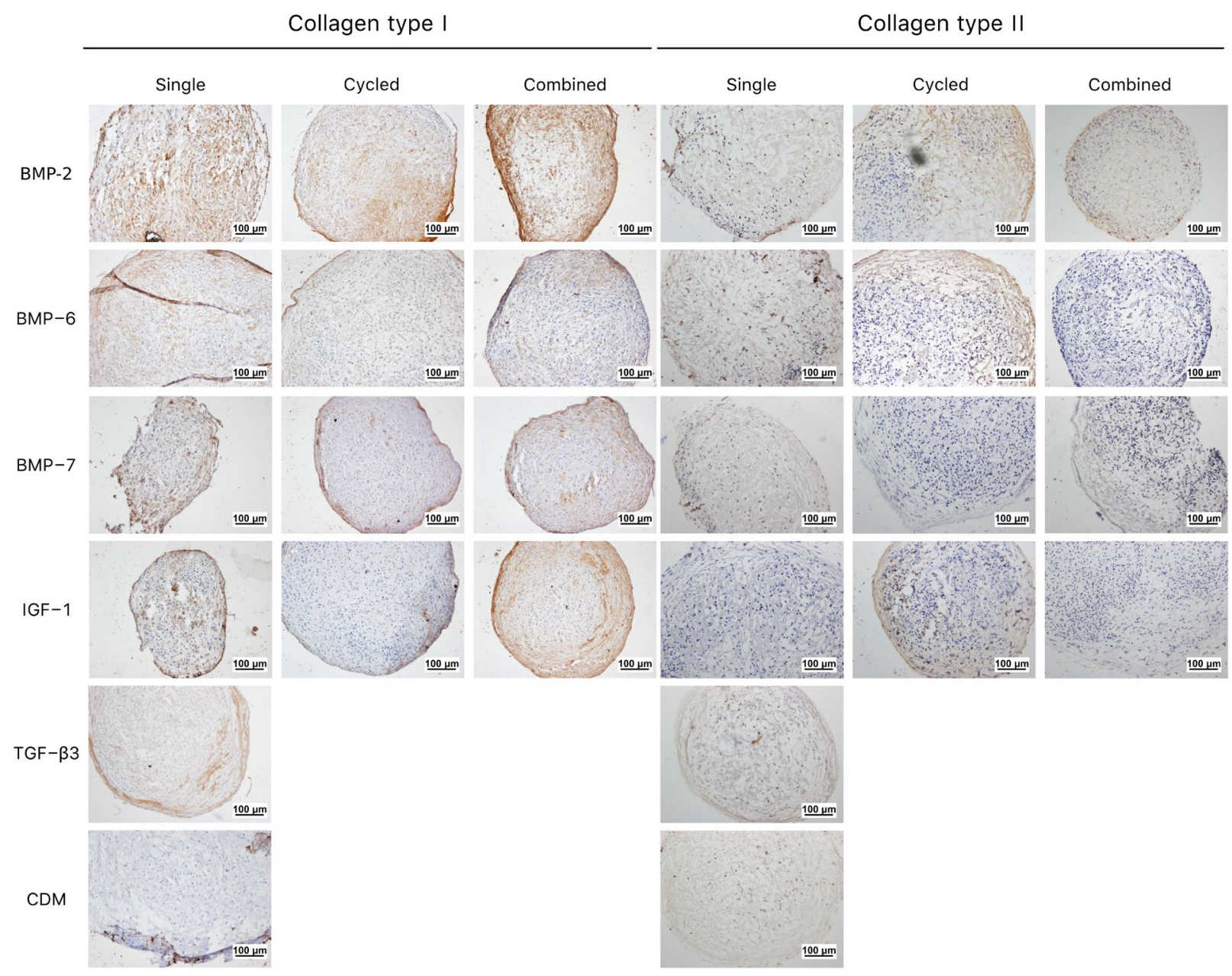

Fig. 8. Effect of the different GFs and their administration patterns on collagen deposition. Immunohistochemical analysis highlighted the presence (brown) of collagen type I (left) and collagen type II (right) after 4 weeks of culture.

\section{Chondrogenic medium}

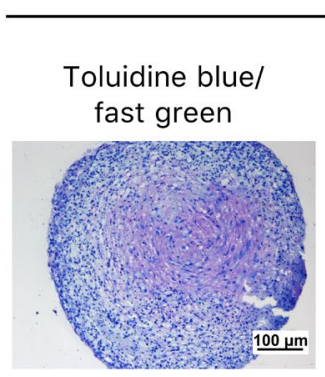

Hypertrophic medium

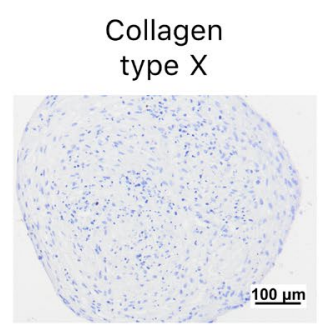

Toluidine blue/
fast green

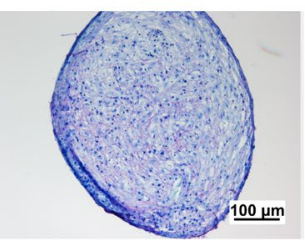

\section{Collagen} type $X$

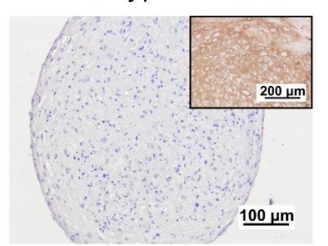

von Kossa

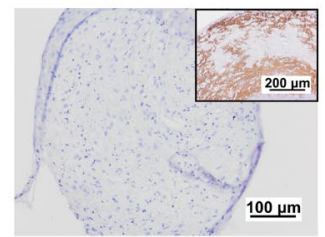

Fig. 9. Hypertrophic marker presence in DPSCs after chondrogenic and hypertrophic induction for $35 \mathrm{~d}$. Positive controls of differentiated BMSCs are depicted in the inserts. 
MSC cultures used as control condition. Interestingly, no COL2A1 expression was detected. This apparent discrepancy between PCR quantification and histological results could be due to several factors, including post-transcriptional regulatory mechanism and difference in speed between the transcription and translation process and in half-life between mRNA and protein (2.6-7 $\mathrm{h}$ for $\mathrm{mRNA}$ versus $46 \mathrm{~h}$ for proteins) (Liu et al., 2016; Vogel and Marcotte, 2012). Similarly, other studies have reported collagen type I expression (Spath et al., 2010; Sternberg et al., 2012) in DPSC pellets and inferior (hyaline) chondrogenic potential when compared to other adult stem cell sources (Alge et al., 2010; Isobe et al., 2016; Koyama et al., 2009; Sternberg et al., 2012). As far as it can be ascertained, only one study explored the potential of using DPSCs embedded in a chitosan/alginate scaffold for the regeneration of the TMJ disc (Bousnaki et al., 2018). Consistent with the present study results, Bousnaki et al. (2018) observed an upregulation of collagen type I gene expression, together with expression of SOX9, aggrecan and COMP during chondrogenic differentiation. These evidences indicated that, although it has been proposed that DPSCs could be applied for hyaline cartilage regeneration (Mata et al., 2017; Nuti et al., 2016), the in vitro deposited ECM had robust characteristics of fibrous cartilage tissue.

Several strategies have been reported in the literature to elicit the limited hyaline chondrogenic differentiation capacity of DPSCs, including transduction with an adeno-associated viral vector to induce TGF- $\beta 3$ expression (Rizk and Rabie, 2013), co-culture with chondrocytes (Dai et al., 2012) and use of nanopatterned hydrogels as a support material (Nemeth et al., 2014). These strategies result in enhanced GAG (Dai et al., 2012; Rizk and Rabie, 2013), collagen type II (Dai et al., 2012; Nemeth et al., 2014; Rizk and Rabie, 2013) and aggrecan (Rizk and Rabie, 2013) deposition. In the present study, the possibility of enhancing DPSC chondrogenesis was evaluated by tailoring the composition of the differentiation medium. This is particularly appealing from a clinical translational perspective, as changing the supplied GFs represents a simpler and more straightforward option to implement. Thus, the present study evaluated if GAGs and collagen type II deposition could be enhanced by supplementing BMP-2, BMP-6, BMP-7 or IGF-1, alone or in combination with TGF- $\beta 3$. These (combinations of) GFs were selected because they are classically used in MSCs chondrogenic differentiation protocols (Vater et al., 2011). Furthermore, BMP-2 and BMP7 are particularly interesting candidates, not only because of their common use to stimulate MSC chondrogenesis, but also because they are expressed in early developing Meckel's cartilage (Wang et al., 2013) and TMJ condyle (Stocum and Roberts, 2018). Finally, since the administration of different GFs in an alternating, cyclic pattern can effectively enhance MSC chondrogenesis (Indrawattana et al., 2004), its effect on DPSC differentiation was assessed. Results showed that culturing DPSC pellets with CDM alone already resulted in limited GAG deposition, which was not enhanced by any of the GFs or patterns evaluated. Remarkably, the combination of BMP$2,-6$ or -7 with TGF- $\beta 3$ resulted in significantly lower GAG/DNA-ratios than when the DPSCs were cultured with either of these factors alone. This suggested that the continuous combination of one of the BMP isoforms with TGF- $\beta 3$ did not have a synergistic effect on DPSC chondrogenesis as observed for example for MSCs and adiposederived stem cells (Shen et al., 2009; Shen et al., 2010). Furthermore, collagen type I remained an abundant component in the ECM in all conditions and the cells maintained an elongated morphology after differentiation, a phenomenon that is typical for fibrochondrocytes (Allen and Athanasiou, 2006). These results further confirmed the DPSC predisposition to produce a fibrocartilaginous matrix under a large variety of chondro-inductive culture conditions.

Finally, the capability of chondrogenically differentiated DPSCs to acquire a hypertrophic phenotype was investigated. Inferior expression of collagen type X as compared to the MSC control was already observed upon chondrogenic induction. In addition, the absence of mineralisation and collagen type $X$ protein deposition after stimulation with both chondrogenic and hypertrophic media indicated that, unlike bone-marrow-derived MSCs (Pelttari et al., 2006), DPSCs did not seem to have the potential to undergo hypertrophy under the differentiation conditions used in the study.

In conclusion, even if DPSCs are defined as MSC-like cells, they respond differently from the classical chondrogenic stimulation protocol for MSCs. The reasons for this behaviour could be multiple. Interestingly, already without any GF stimulation, the expression of chondro-related genes is dissimilar between MSCs and DPSCs. These differences dramatically increase upon chondrogenic stimulation in a micromass model system (Sternberg et al., 2012). Comparably, other studies have previously reported a different extent of GAG and collagen type II production by MSCs isolated from different tissues (Isobe et al., 2016) or within different regions of the same tissue (Sivasubramaniyan et al., 2019) upon stimulation with the same chondrogenic medium. Even though the reason behind this heterogeneity in chondrogenic differentiation response is not clear, it can be hypothesised that it correlates with the presence of different GFs in the natural microenvironment (Sivasubramaniyan et al., 2019), a different epigenetic profile or a different cell origin.

\section{Conclusions}

The results indicated that, despite existing indications that DPSCs could be used for engineering hyaline cartilage (Mata et al., 2017) and hypertrophic chondrogenic tissues (Kruijt Spanjer et al., 2017), 
these cells would be more suitable for engineering of fibrocartilaginous tissues, including the disc and condylar cartilage, for TMJ regeneration.

\section{Acknowledgements}

This study was part of project number AOCMF17-17G, supported by the AO Foundation, Davos, Switzerland. Part of the study was also supported by the BOOA research grant of the NVMKA. The antibody against collagen type II (II-II6B3), developed by T.F. Linsenmayer, was obtained from the DSHB developed under the auspices of the NICHD and maintained by The University of Iowa, Department of Biology, Iowa City, IA 52242, USA.

The authors declare no conflict of interest.

\section{References}

Alge DL, Zhou D, Adams LL, Wyss BK, Shadday MD, Woods EJ, Gabriel Chu TM, Goebel WS (2010) Donor-matched comparison of dental pulp stem cells and bone marrow-derived mesenchymal stem cells in a rat model. J Tissue Eng Regen Med 4: 73-81.

Allen KD, Athanasiou KA (2006) Tissue engineering of the TMJ disc: a review. Tissue Eng 12: $1183-1196$.

Alvarez R, Lee HL, Hong C, Wang CY (2015) Single CD271 marker isolates mesenchymal stem cells from human dental pulp. Int J Oral Sci 7: 205-212.

Anitua E, Troya M, Zalduendo M (2018) Progress in the use of dental pulp stem cells in regenerative medicine. Cytotherapy 20: 479-498.

Bousnaki M, Bakopoulou A, Papadogianni D, Barkoula NM, Alpantaki K, Kritis A, Chatzinikolaidou M, Koidis P (2018) Fibro/chondrogenic differentiation of dental stem cells into chitosan/alginate scaffolds towards temporomandibular joint disc regeneration. J Mater Sci Mater Med 29: 97. DOI: 10.1007/s10856018-6109-6.

Caron MM, Emans PJ, Coolsen MM, Voss L, Surtel DA, Cremers A, van Rhijn LW, Welting TJ (2012) Redifferentiation of dedifferentiated human articular chondrocytes: comparison of 2D and 3D cultures. Osteoarthritis Cartilage 20: 1170-1178.

Chai Y, Jiang X, Ito Y, Bringas P Jr, Han J, Rowitch DH, Soriano P, McMahon AP, Sucov HM (2000) Fate of the mammalian cranial neural crest during tooth and mandibular morphogenesis. Development 127: 1671-1679.

Collignon AM, Castillo-Dali G, Gomez E, Guilbert T, Lesieur J, Nicoletti A, Acuna-Mendoza S, Letourneur D, Chaussain C, Rochefort GY, Poliard A (2019) Mouse Wnt1-CRE-Rosa ${ }^{\text {Tomato }}$ dental pulp stem cells directly contribute to the calvarial bone regeneration process. Stem Cells 37: 701-711.

Dai J, Wang J, Lu J, Zou D, Sun H, Dong Y, Yu H, Zhang L, Yang T, Zhang X, Wang X, Shen G (2012) The effect of co-culturing costal chondrocytes and dental pulp stem cells combined with exogenous FGF9 protein on chondrogenesis and ossification in engineered cartilage. Biomaterials 33: 7699-7711.

Farndale RW, Buttle DJ, Barrett AJ (1986) Improved quantitation and discrimination of sulphated glycosaminoglycans by use of dimethylmethylene blue. Biochim Biophys Acta 883: 173-177.

Gawlitta D, Farrell E, Malda J, Creemers LB, Alblas J, Dhert WJA (2010) Modulating endochondral ossification of multipotent stromal cells for bone regeneration. Tissue Eng Part B Rev 16: 385-395.

Gawlitta D, van Rijen MH, Schrijver EJ, Alblas J, Dhert WJ (2012) Hypoxia impedes hypertrophic chondrogenesis of human multipotent stromal cells. Tissue Eng Part A 18: 1957-1966.

Graziano A, d'Aquino R, Laino G, Papaccio G (2008) Dental pulp stem cells: a promising tool for bone regeneration. Stem Cell Rev 4: 21-26.

Gronthos S, Mankani M, Brahim J, Robey PG, Shi S (2000) Postnatal human dental pulp stem cells (DPSCs) in vitro and in vivo. Proc Natl Acad Sci U S A 97: 13625-13630.

Grottkau BE, Purudappa PP, Lin YF (2010) Multilineage differentiation of dental pulp stem cells from green fluorescent protein transgenic mice. Int J Oral Sci 2: 21-27.

Hilkens P, Gervois P, Fanton Y, Vanormelingen J, Martens W, Struys T, Politis C, Lambrichts I, Bronckaers A (2013) Effect of isolation methodology on stem cell properties and multilineage differentiation potential of human dental pulp stem cells. Cell Tissue Res 353: 65-78.

Indrawattana N, Chen G, Tadokoro M, Shann LH, Ohgushi H, Tateishi T, Tanaka J, Bunyaratvej A (2004) Growth factor combination for chondrogenic induction from human mesenchymal stem cell. Biochem Biophys Res Commun 320: 914-919.

Iohara K, Zheng L, Ito M, Tomokiyo A, Matsushita K, Nakashima M (2006) Side population cells isolated from porcine dental pulp tissue with self-renewal and multipotency for dentinogenesis, chondrogenesis, adipogenesis, and neurogenesis. Stem Cells 24: 24932503.

Isobe Y, Koyama N, Nakao K, Osawa K, Ikeno M, Yamanaka S, Okubo Y, Fujimura K, Bessho K (2016) Comparison of human mesenchymal stem cells derived from bone marrow, synovial fluid, adult dental pulp, and exfoliated deciduous tooth pulp. Int J Oral Maxillofac Surg 45: 124-131.

Koyama N, Okubo Y, Nakao K, Bessho K (2009) Evaluation of pluripotency in human dental pulp cells. J Oral Maxillofac Surg 67: 501-506.

Kruijt Spanjer EC, Bittermann GKP, van Hooijdonk IEM, Rosenberg A, Gawlitta D (2017) Taking the endochondral route to craniomaxillofacial bone regeneration: a logical approach? J Craniomaxillofac Surg 45: 1099-1106.

La Noce M, Mele L, Laino L, Iolascon G, Pieretti G, Papaccio G, Desiderio V, Tirino V, Paino F (2019) Cytoplasmic interactions between the glucocorticoid receptor and HDAC2 regulate osteocalcin expression 
in VPA-treated MSCs. Cells 8. pii: E217. DOI: 10.3390/ cells8030217.

Liu Y, Beyer A, Aebersold R (2016) On the dependency of cellular protein levels on mRNA abundance. Cell 165: 535-550.

Mata M, Milian L, Oliver M, Zurriaga J, SanchoTello M, de Llano JJM, Carda C (2017) In vivo articular cartilage regeneration using human dental pulp stem cells cultured in an alginate scaffold: a preliminary study. Stem Cells Int 2017: 8309256. DOI: 10.1155/2017/8309256.

Mokry J, Soukup T, Micuda S, Karbanova J, Visek B, Brcakova E, Suchanek J, Bouchal J, Vokurkova D, Ivancakova R (2010) Telomere attrition occurs during ex vivo expansion of human dental pulp stem cells. J Biomed Biotechnol 2010: 673513. DOI: 10.1155/2010/673513.

Morad G, Kheiri L, Khojasteh A (2013) Dental pulp stem cells for in vivo bone regeneration: a systematic review of literature. Arch Oral Biol 58: 1818-1827.

Nemeth CL, Janebodin K, Yuan AE, Dennis JE, Reyes M, Kim DH (2014) Enhanced chondrogenic differentiation of dental pulp stem cells using nanopatterned PEG-GelMA-HA hydrogels. Tissue Eng Part A 20: 2817-2829.

Nuti N, Corallo C, Chan BMF, Ferrari M, GeramiNaini B (2016) Multipotent differentiation of human dental pulp stem cells: a literature review. Stem Cell Rev Rep 12: 511-523.

Paino F, La Noce M, Giuliani A, De Rosa A, Mazzoni S, Laino L, Amler E, Papaccio G, Desiderio V, Tirino V (2017) Human DPSCs fabricate vascularized woven bone tissue: a new tool in bone tissue engineering. Clin Sci (Lond) 131: 699-713.

Pelttari K, Winter A, Steck E, Goetzke K, Hennig T, Ochs BG, Aigner T, Richter W (2006) Premature induction of hypertrophy during in vitro chondrogenesis of human mesenchymal stem cells correlates with calcification and vascular invasion after ectopic transplantation in SCID mice. Arthritis Rheum 54: 3254-3266.

Pereira LO, Rubini MR, Silva JR, Oliveira DM, Silva IC, Pocas-Fonseca MJ, Azevedo RB (2012) Comparison of stem cell properties of cells isolated from normal and inflamed dental pulps. Int Endod J 45: 1080-1090.

Pierdomenico L, Bonsi L, Calvitti M, Rondelli D, Arpinati M, Chirumbolo G, Becchetti E, Marchionni C, Alviano F, Fossati V, Staffolani N, Franchina M, Grossi A, Bagnara GP (2005) Multipotent mesenchymal stem cells with immunosuppressive activity can be easily isolated from dental pulp. Transplantation 80: 836-842.

Ponnaiyan D, Jegadeesan V (2014) Comparison of phenotype and differentiation marker gene expression profiles in human dental pulp and bone marrow mesenchymal stem cells. Eur J Dent 8: 307313.

Puetzer JL, Petitte JN, Loboa EG (2010) Comparative review of growth factors for induction of threedimensional in vitro chondrogenesis in human mesenchymal stem cells isolated from bone marrow and adipose tissue. Tissue Eng Part B Rev 16: 435-444.

Rizk A, Rabie AB (2013) Human dental pulp stem cells expressing transforming growth factor $\beta 3$ transgene for cartilage-like tissue engineering. Cytotherapy 15: 712-725.

Shen B, Wei A, Tao H, Diwan AD, Ma DD (2009) BMP-2 enhances TGF-beta3-mediated chondrogenic differentiation of human bone marrow multipotent mesenchymal stromal cells in alginate bead culture. Tissue Eng Part A 15: 1311-1320.

Shen B, Wei A, Whittaker S, Williams LA, Tao H, Ma DD, Diwan AD (2010) The role of BMP-7 in chondrogenic and osteogenic differentiation of human bone marrow multipotent mesenchymal stromal cells in vitro. J Cell Biochem 109: 406-416.

Sivasubramaniyan K, Koevoet WJLM, Hakimiyan AA, Sande M, Farrell E, Hoogduijn MJ, Verhaar JAN, Chubinskaya S, Bühring HJ, van Osch GJVM (2019) Cell-surface markers identify tissue resident multipotential stem/stromal cell subsets in synovial intimal and sub-intimal compartments with distinct chondrogenic properties. Osteoarthritis Cartilage 27: 1831-1840.

Sophia Fox AJ, Bedi A, Rodeo SA (2009) The basic science of articular cartilage: structure, composition, and function. Sports Health 1: 461-468.

Spath L, Rotilio V, Alessandrini M, Gambara G, De Angelis L, Mancini M, Mitsiadis TA, Vivarelli E, Naro F, Filippini A, Papaccio G (2010) Explant-derived human dental pulp stem cells enhance differentiation and proliferation potentials. J Cell Mol Med 14: 16351644.

Sternberg H, Murai JT, Erickson IE, Funk WD, Das S, Wang Q, Snyder E, Chapman KB, Vangsness CT Jr, West MD (2012) A human embryonic stem cellderived clonal progenitor cell line with chondrogenic potential and markers of craniofacial mesenchyme. Regen Med 7: 481-501.

Stocum DL, Roberts WE (2018) Part I: development and physiology of the temporomandibular joint. Curr Osteoporos Rep 16: 360-368.

Takebe Y, Tatehara S, Fukushima T, TokuyamaToda R, Yasuhara R, Mishima K, Satomura K (2017) Cryopreservation method for the effective collection of dental pulp stem cells. Tissue Eng Part C Methods 23: 251-261.

Tamaki Y, Nakahara T, Ishikawa H, Sato S (2013) In vitro analysis of mesenchymal stem cells derived from human teeth and bone marrow. Odontology 101: 121-132.

Tirino V, Paino F, De Rosa A, Papaccio G (2012) Identification, isolation, characterization, and banking of human dental pulp stem cells. Methods Mol Biol 879: 443-463.

Vater C, Kasten P, Stiehler M (2011) Culture media for the differentiation of mesenchymal stromal cells. Acta Biomater 7: 463-477.

Vogel C, Marcotte EM (2012) Insights into the regulation of protein abundance from proteomic and transcriptomic analyses. Nat Rev Genet 13: 227-232. 
Wang Y, Zheng Y, Chen D, Chen Y (2013) Enhanced BMP signaling prevents degeneration and leads to endochondral ossification of Meckel's cartilage in mice. Dev Biol 381: 301-311.

Yoo JU, Barthel TS, Nishimura K, Solchaga L, Caplan AI, Goldberg VM, Johnstone B (1998) The chondrogenic potential of human bone-marrowderived mesenchymal progenitor cells. J Bone Joint Surg Am 80: 1745-1757.

Zhang W, Walboomers XF, Shi S, Fan M, Jansen JA (2006) Multilineage differentiation potential of stem cells derived from human dental pulp after cryopreservation. Tissue Eng 12: 2813-2823.

\section{Discussion with Reviewers}

Piefrancesco Pagella: How do the authors explain the poor tendency to form hyaline-like cartilage of DPSCs in their in vitro system, compared to previous reports? Authors: One of the major differences between the present study and previous work where chondrogenic differentiation is claimed, is that the present study used a 3D pellet model rather than a 2D culture system (Alge et al., 2010; Alvarez et al., 2015; Pereira et al., 2012). When 3D pellets are used, other authors have also reported inferior chondrogenic potential and lower presence of hyaline markers when compared to other cell types (Sternberg et al., 2012; Sivasubramaniyan et al., 2019; Pierdomenico et al., 2005). This poor tendency to differentiate into hyaline-like cartilage could be attributed to the fact that even if DPSCs are defined as MSC-like cells, they upregulate different chondro-related genes when compared to the bone marrow-derived stem cells after chondrogenic induction (Sternberg et al., 2012). Thus, it is possible that they require different stimuli to produce a more hyaline-like cartilaginous matrix.

Giovanna Orsini: Can the authors point out the future clinical implications of their work?

Authors: DPSCs have been mainly investigated for their application potential in bone regeneration and dentistry (Anitua et al., 2018; Morad et al., 2013). However, contrasting evidence exists regarding their suitability for cartilage TE. In addition, most of the efforts have been focused on the regeneration of hyaline cartilage (Sternberg et al., 2012; Zhang et al., 2006). The present study proposed a new and rather unexplored application of DPSCs. The capability of DPSCs to secrete collagen type I and retain a fibrochondrocytes morphology under different stimuli makes them a viable option for fibrocartilage TE. This predisposition towards secreting ECM components typical of fibrocartilage, together with the simplicity of the DPSC isolation procedure as well as their high proliferative potential, makes them particularly attractive for clinical application when compared to other cell types. Finally, their use could be envisioned for the regeneration of various types of fibrocartilaginous tissues, including the mandibular condylar cartilage, menisci and intervertebral disc.

Anne Poliard: It is possible that collagen type II mRNA expression was already downregulated at day 21. Could this be shown with an earlier time point real-time PCR? Could it be that the antibody used recognised type IIA and IIB isoforms while primers would be specific of type IIB.

Authors: Although we understand that this might provide valuable information about the temporal pattern of COL2A1 expression in DPSCs, we truly believe that this is beyond the scope of the study. The goal of the work was to determine the chondrogenic potential of DPSCs with regard to their application for engineering hyaline cartilage or fibrous cartilage. The data presented were sufficient to justify the conclusions as, next to the limited production of collagen type II protein, the presence of abundant collagen type I at the protein level, the upregulation of COL1A1 expression as well as expression of other cartilage matrix genes and the cell morphology were shown. These data combined supported the conclusion that DPSCs are more suitable for fibrous cartilage engineering. In addition, throughout the manuscript, we never claimed an extensive collagen type II deposition, even at the protein level. In contrast, we highlighted that it was rather limited, making DPSCs unsuitable for hyaline cartilage engineering when following the various methods. Thus, even if we would provide additional data on COL2A1 expression at earlier time points, this would not change the conclusions presented.

Editor's note: The Scientific Editor responsible for this paper was Thimios Mitsiadis. 